\title{
Docentes que hacen la diferencia
}

Alejandra Ivonne Amador Franco

$\mathrm{E}$ n este artículo se presentan una serie de ideas que invitan a reflexionar sobre la práctica docente; la pregunta que detona este ejercicio es: ¿cómo ser un docente de excelencia? El lector recorrerá diversos argumentos que al final concluyen en lo que ya antes autores como Reyero (2014: 136) han señalado: “el corazón de la enseñanza universitaria se encuentra en el carácter relacional de la misma".

Una de las inquietudes que a menudo tenemos los docentes, incluso antes de serlo, es si seremos capaces de influir de manera positiva en los estudiantes. Evolucionamos, aprendemos, reaprehendemos, conocemos nuevos enfoques, teorías, nos enfrentamos a nuevas políticas y quizás lo único que permanece constante en nuestra mente, es el siguiente cuestionamiento: ¿cuáles son las características que hacen a algunos profesores excepcionales, mientras que otros pasan "desapercibidos"?, ¿cómo seremos para los alumnos lo que alguna vez fue para nosotros ese profesor que hizo la diferencia y terminó por orientar o reorientar nuestro camino?, ¿cómo puedo convertirme en esa persona que, en palabras de Shahar (2015), riegue la semilla que ya cuenta con un enorme potencial para florecer?

En general, el hecho educativo ha sido estudiado, cuestionado y criticado desde diferentes aristas, que pocas veces incluyen la variable de las relaciones (vínculos) que se desarrollan entre pro- fesores y estudiantes. En las conferencias, talleres, ponencias y cursos de actualización, se habla de nuevas tecnologías de la información, innovadores modelos educativos que sugieren diversas estrategias para el proceso de enseñanza-aprendizaje, la llegada de la educación a distancia, problemáticas recurrentes como el bullying, entre otros más, pero casi nunca se escucha hablar sobre lo que espléndidamente Pierson (2013), educadora por más de 40 años, argumenta sobre el éxito de cualquier curso académico: el poder de la conexión, es decir, el vínculo que se genera entre docentes y alumnos.

Pierson (2013) menciona que, en general, sabemos con facilidad qué factores pueden entorpecer el proceso de aprendizaje de los alumnos, aunque pocas veces los docentes reflexionamos sobre el hecho de que, probablemente, nosotros formemos parte de esos elementos que interfieren con el proceso de aprendizaje, e incluso con el crecimiento de los estudiantes como personas. Conocemos todo sobre aquello que, de manera externa, puede afectar al acto educativo: reformas, políticas inadecuadas, padres omisos, negligentes, autoritarios, instituciones debilitadas, autoridades poco competentes, entre otras situaciones más. Pero, ¿qué sucedería si pudiéramos regresar la mirada a nuestra propia contribución? ¿Qué pasaría si pensáramos en lo que sí podemos ofrecer como docentes a nuestros estudiantes en lugar de considerar todo aquello que no 
se nos da, se nos quita o se nos niega? La principal herramienta de trabajo que tenemos, aún a pesar de las múltiples carencias, somos nosotros mismos; nosotros como seres humanos que se conectan con otros seres humanos.

En ese sentido, existen diversos estudios que sustentan la premisa de que el poder de la conexión/ relación que se desarrolla entre el profesor y el estudiante, es una de las variables más importantes que predice el exitoso desempeño escolar de los estudiantes. Por ejemplo, en un estudio longitudinal realizado por Harme y Pianta (2001, citado en Woolfolk, 2010), en el que llevaron a cabo un seguimiento del rendimiento escolar de todos los preescolares de un jardín de niños hasta la escuela secundaria, concluyeron que la asociación entre la calidad de las relaciones tempranas profesor-niño y el desempeño escolar posterior podría ser fuerte y persistente. Los autores definieron la relación entre maestro-alumno considerando los siguientes elementos: nivel de conflicto o aceptación con el niño, dependencia del infante hacia el profesor y el afecto que este último mostraba hacia el alumno.

Harme y Pianta (2001) encontraron también que los efectos de un vínculo positivo tenían mucho más impacto en los niños que presentaban problemas de conducta. Esto puede trasladarse también al contexto educativo universitario; en un amplio estudio que buscó caracterizar la práctica docente de 67 profesores norteamericanos considerados de excelencia, Bain (2007: 11) se encontró que una de las características principales de los profesores muy efectivos es que "tienden a mostrar una gran confianza en los estudiantes, habitualmente están seguros de que éstos quieren aprender, $\mathrm{y}$ asumen, mientras no se les demuestre lo contrario, que pueden hacerlo." Según el autor, los docentes de excelencia se muestran abiertos con los estudiantes, con un profundo respeto y curiosidad por su vida y, sobre todo, los tratan de manera amable; si bien Bain no lo menciona, estos elementos sin duda forman parte de lo que se considera un vínculo positivo entre profesor y estudiante, factor que como se ha dicho, hace la diferencia.

En esa línea, Shahar (2015), prominente estudioso de la psicología positiva, se ha encarga- do de retomar diversas investigaciones en las que se demuestra cómo las altas expectativas que los docentes tienen sobre sus estudiantes, determinan de manera importante el éxito escolar que ellos puedan tener. La primera de estas investigaciones se realizó en los años 60, cuando Rosenthal y Jacobsen (1968) desarrollaron un experimento en el que encontraron el famoso "Efecto Pigmalión". En breves palabras, el estudio consistió en que a los profesores de diversas escuelas en Estados Unidos, elegidas al azar, se les comentó que sus alumnos harían un test para ubicar qué personas podían "desarrollarse" rápidamente durante el siguiente año; esto significaba que los estudiantes que obtuvieran puntuaciones altas, tendrían muchas posibilidades de tener un amplio desarrollo intelectual y un buen rendimiento escolar durante ese ciclo. En realidad, esto no fue cierto, el test que se les dio a los alumnos era uno que medía inteligencia, pero que nada tenía que ver con la capacidad para predecir el potencial de desarrollo intelectual de una persona. Los resultados fueron entregados a los profesores, se les mostró qué alumnos habían obtenido puntajes "altos" (aunque en realidad fueron elegidos al azar de un sombrero), y lo que se encontró posteriormente, fue que esos alumnos, al terminar el ciclo escolar, efectivamente habían logrado mejorar su rendimiento de manera importante, y no sólo eso, estos chicos, pasado un año, continuaron mostrando mejorías e incluso lograron cambios significativos en su coeficiente intelectual.

Rosenthal y Jacobsen (1968) concluyeron, entonces, que las altas expectativas de los profesores inciden en el desarrollo de los estudiantes. Es decir, si los docentes "creen" en el potencial de crecimiento de sus estudiantes, seguramente se acercarán a ellos desde una postura muy diferente, a que si los catalogan y etiquetan como "problema", "inestables", "incapaces", "disruptivos", "ineficaces"; entre otros tantos adjetivos que denotan que el nivel de expectativas que hay sobre ellos, tanto de padres como de docentes, es muy bajo. ¿Qué se obtendrá entonces? Seguramente resultados pobres, pero, ¿qué sucede si alguien logra encontrar en ellos una semilla de grandeza?, ¿algo para lo que sí sean efi- 
caces? ¿Qué pasaría si alguien decidiera confiar en ellos y se atreviera a vincularse de una forma cálida, cercana, empática y respetuosa de su experiencia de vida?

Ahora bien, es necesario mantener un enfoque centrado en la positividad como lo sugiere Shahar (2015), es decir, una mirada concentrada en los recursos que las personas poseen, lo cual no significa que como docentes construiremos falsas expectativas sobre los estudiantes. La positividad debe estar fundamentada; las altas expectativas deben descansar en recursos con los que el alumno ya cuenta y nuestra labor reside en ubicarlos, recuperarlos y potencializarlos.

\section{Conclusiones}

Más allá de lo que rodea el acto educativo, los docentes debemos -también- reflexionar sobre el tipo de relaciones que construimos. Nuestras explicaciones deterministas y reduccionistas sobre los estudiantes -tiene problemas con la autoridad, es rebelde, tiene fallas en el control de impulsos, es hiperactivo-, nos distancian de ellos y nos colocan como un obstáculo más a vencer. Hay mucha más responsabilidad para el docente al pedirle que logre apreciar lo que sus alumnos pueden ofrecerle. De igual forma, cabe mencionar que el enfoque basado en la competencia no es igual a negar aquellas situaciones "negativas" que interfieren y afectan al proceso; más bien, la mirada debe apuntar también a lo que sí funciona (Shahar, 2015). Las carencias ya han sido muy estudiadas desde diversas ciencias que incluyen a la educación, ¿por qué no concentrarse ahora en lo que sí funciona? Al final, como sencilla pero profundamente señala Bain (2007): todo se resume a que los mejores profesores siempre esperan "más" de sus estudiantes.

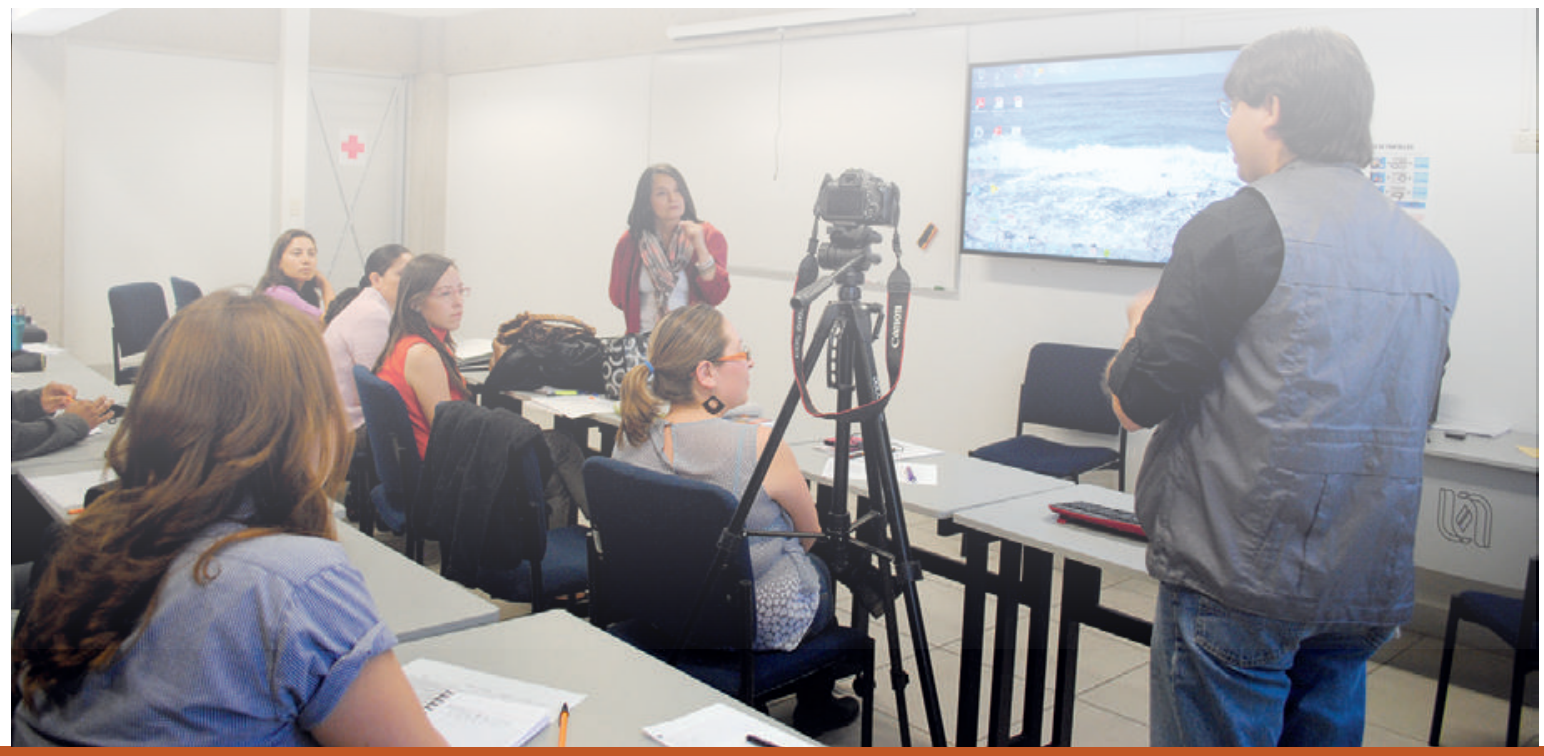

Fuentes de consulta

Bain, K. (2007). Lo que hacen los mejores profesores de universidad. España: Universidad de Valencia.

Pierson, R. (2013, mayo). Rita Pierson: Todo niño necesita un campeón. [Archivo en video]. Recuperado el 24 de agosto de 2016, en: http://bit.ly/1OLu8rL.

Reyero, D. (2014). La excelencia docente universitaria. Análisis y propuestas para una mejor evaluación del profesorado universitario. Revista Educación XXI, 17(2), 125-143.
Rosenthal, R. y Jacobsen, L. (1968). Pygmalion in the classroom: teacher expectation and pupils'intellectual development. New York: Holt, Rinehart and Winston.

Shahar, T. (2015). Introducción a la psicología positiva. Conferencia presentada en el Diplomado en Bienestar, Felicidad y Resiliencia. México: Instituto de Bienestar Integral.

Woolfolk, A. (2010). Psicología educativa. $\left(11^{\mathrm{a}}\right.$ edición). México: Prentice Hall. 